Article

\title{
Photocracking Silica: Tuning the Plasmonic Photothermal Degradation of Mesoporous Silica Encapsulating Gold Nanoparticles for Cargo Release
}

\author{
Jonas G. Croissant ${ }^{1,2, *}$ and Tania M. Guardado-Alvarez ${ }^{3}$ \\ 1 Chemical and Biological Engineering, University of New Mexico, 210 University Blvd NE, \\ Albuquerque, NM 87131-0001, USA \\ 2 Center for Micro-Engineered Materials, Advanced Materials Laboratory, University of New Mexico, \\ MSC04 2790, 1001 University Blvd SE, Suite 103, Albuquerque, NM 87106, USA \\ 3 Department of Chemistry and Biochemistry, University of California Los Angeles, \\ Los Angeles, CA 90095, USA; guardado@chem.ucla.edu \\ * Correspondence: jonasc@chem.ucla.edu
}

Received: 6 May 2019; Accepted: 31 May 2019; Published: 6 June 2019

\begin{abstract}
The degradation of bionanomaterials is essential for medical applications of nanoformulations, but most inorganic-based delivery agents do not biodegrade at controllable rates. In this contribution, we describe the controllable plasmonic photocracking of gold@silica nanoparticles by tuning the power and wavelength of the laser irradiation, or by tuning the size of the encapsulated gold cores. Particles were literally broken to pieces or dissolved from the inside out upon laser excitation of the plasmonic cores. The photothermal cracking of silica, probably analogous to thermal fracturing in glass, was then harnessed to release cargo molecules from gold@silica@polycaprolactone nanovectors. This unique and controllable plasmonic photodegradation has implications for nanomedicine, photopatterning, and sensing applications.
\end{abstract}

Keywords: degradation; plasmonic; gold nanoparticles; mesoporous silica nanoparticles; photothermal; polymer coating

\section{Introduction}

Engineering bioinorganic nanomaterials with controllable degradability rates is essential to prevent toxic bioaccumulation into the body after their diagnostic or therapeutic intended purposes [1-4]. Among bioinorganic nanomaterials [5], mesoporous silica and organosilica nanoparticles (NPs) are promising hybrid nanomaterials for biomedical applications [6,7]. Silica particles have indeed many unique benefits such as tunable dissolution rates from under a day to months [1], high surface areas and pore volumes (e.g., 1000-1500 $\mathrm{m}^{2} \cdot \mathrm{g}^{-1} ; 1.0-4.5 \mathrm{~cm}^{3} \cdot \mathrm{g}^{-1}$ ) $[8,9]$, and can be produced in kilogram quantities while maintaining a high control of particle monodispersity [10]. Silica can be hybridized using organic and inorganic doping strategies to mediate biodegradability through $\mathrm{pH}[11,12]$, enzymatic [12-14], redox [3,15-18], and biochelation [19-22] mechanisms [1,2]. The controlled silicon chemistry and hybridization of silica NPs also enables controlled surface modifications for various applications [6,23-28] including drug delivery [6,29-32] and medical diagnosis [33-35].

Plasmonic NPs are increasingly used as photothermal (PT) transducers for a wide variety of applications in colloidal and surface sciences [36-43]. The control of the PT efficacy of various metal NPs has numerous potential applications as witnessed by the increasing number of theoretical and experimental studies [36-38,44-50]. Detailed studies of the PT efficacies of gold NPs revealed high-energy bleaching of NIR resonant bands for gold shells and rods (the relative PT efficacy decreased by 16-22 times), which was not observed for gold spheres [51]. Gold nanospheres are transducers that 
can produce very high local temperatures. Plasmonic NPs are often embedded within various shells or matrices for biomedical applications using the PT effects. Gold NPs are typically coated with polymers (e.g., polyethylene glycol) to maintain long circulation times in the bloodstream and promote their accumulation into cancer cells [52]. In addition, neutral polymers, liposomes [53], polyelectrolytes [54], and mesoporous silica shells have been coated onto gold NPs to combine the loading properties of the coating matrices with the PT features of the plasmonic cores [55]. Regarding the PT degradation is silica, one hundred nanometer-large silica particles encapsulated inside an $18 \mathrm{~nm}$-thick gold shell were dissolved by a powerful near-infrared (NIR) femtosecond pulsed irradiation ( $90 \mathrm{fs}$ pulses; $1 \mathrm{kHz}$; $1 \mathrm{~mJ} /$ pulse; total energy of $180 \mu \mathrm{J}$ ) [56]. The PT effect even disrupted gold shells at higher power $(300 \mu \mathrm{J})$ [56]. Croissant and Zink also discovered that silica could be dissolved upon PT actuation at low power [57]. Taken together, these studies have demonstrated that PT effects can be used to photodegrade silica-based nanomaterials, however, the parameters governing the photodegradation have not been identified and doing so would allow the control of biodegradability rates for safe and effective biomedical applications.

Herein, we report the surprisingly powerful PT silica cracking in Au@MSN by tuning the size of gold nanocores, or the power and wavelength of the laser irradiation in the visible region (Figure 1). To demonstrate these features, we designed two types of Au@MSN, one containing monodisperse $15 \mathrm{~nm}$-wide gold nanocores, and another encapsulating polydisperse gold NPs of sizes ranging from 5-40 nm. On the one hand, Au@MSN containing monodisperse gold cores were used to study the influence of the laser power on the photocracking. On the other hand, Au@MSN containing polydisperse gold cores were used to demonstrate the influence of the gold diameter and laser wavelength on the silica photodegradation. Finally, the usefulness of the tunable PT degradation of silica was highlighted using Au@MSN@Polycaprolactone (PCL) nanovectors to release cargo molecules upon laser excitation. This unique and controllable plasmonic photodegradation has implications for nanomedicine, photopatterning, and sensing applications.

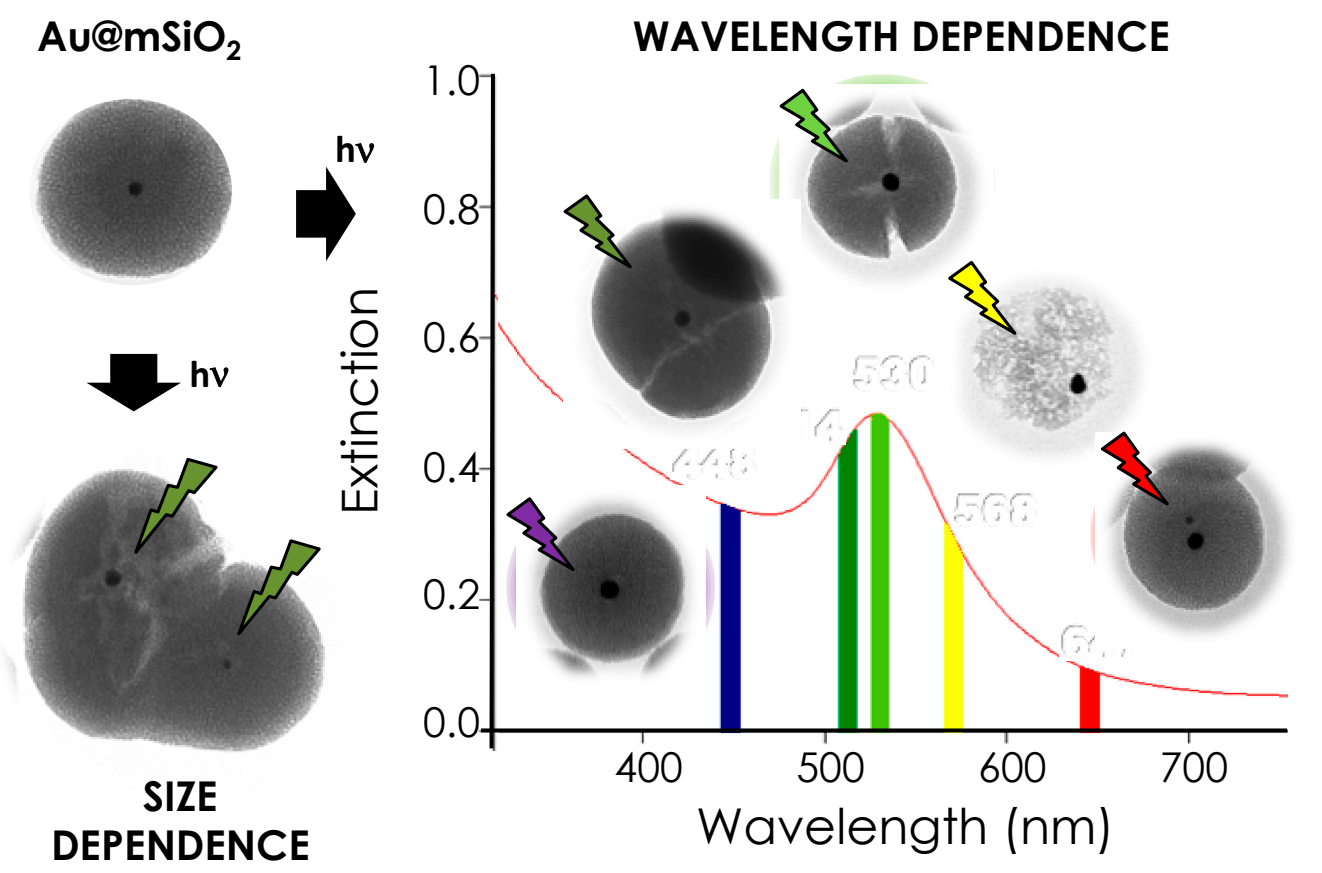

Figure 1. Photodegradation of mesoporous silica nanoparticles encapsulating gold nanocores is dependent on the size of the gold cores and the wavelength of the irradiation.

\section{Results and Discussion}

In view of monitoring the effect of the laser power on the silica photocracking independently of the gold nanoparticle diameter (which impacts the photothermal efficiency [58]), we first prepared 
Au@MSN containing monodisperse 15 nm-wide gold nanospheres. We used the well-established and robust Turkevich method to prepare the monodisperse gold particles $[59,60]$, and then added them to an aqueous solution containing cetyltrimethylammonium bromide (CTAB) surfactants and sodium hydroxide. We finally added TEOS and to obtain Au@MSN with the sol-gel process. The as-prepared Au@MSN nanomaterials displayed a narrow size distribution centered at $150 \mathrm{~nm}$, had a surface area of about $870 \mathrm{~m}^{2} \cdot \mathrm{g}^{-1}$ and average pore sizes of $2.2 \mathrm{~nm}$ (Figures S1 and S2). The mesoporous silica shell had an average thickness of $69 \pm 10 \mathrm{~nm}$ (Figure S3, see Supplementary Materials).

The plasmonic photodegradation of silica was first investigated by monitoring the integrity of the mesoporous silica framework stability before and after irradiation Au@MSN samples via transmission electron microscopy (TEM). The experiments were carried out by directing a laser beam on nanoparticle powders ( $\sim 2 \mathrm{mg}$ ) placed at the bottom of quartz cuvettes filled with deionized water $(\sim 2 \mathrm{~mL})$ [57]. The remarkable silica photodegradation is shown by TEM micrographs before and after $7 \mathrm{~h}$ of irradiation (514 nm, $50 \mathrm{~mW}$ ) of Au@MSN (Figure 2A,B respectively). The qualitative comparison in Figure 2C shows the increasing photodegradation of silica (different particles are compared after the same irradiation time). The PT conversion evolution (Figure 2C) is the result of the experimental fact that all the NPs are not receiving the same treatment under the irradiation geometry used (see Materials and Methods Section). The cause of the silica cracking is clearly the PT effect from the gold cores as implied by the inside out degradation patterns. TEM images strongly suggested growing internal holes which eventually lead to the cracking of the particles (Figure 2B,C). Besides, the holes or cracks present within Au@MSN did not always match the spatial position of the gold cores (see Figure 2B,C and Figure $4 \mathrm{~A}$ at $530 \mathrm{~nm}$ ) which suggests that that the destruction of silica was not primarily due to the vibration of gold NPs under irradiation, but rather to the PT degradation of the weakest parts of the porous silica framework. Going a step further, we decided to assess the possibility of regulating the plasmonic PT efficacy using various irradiation powers and wavelengths.
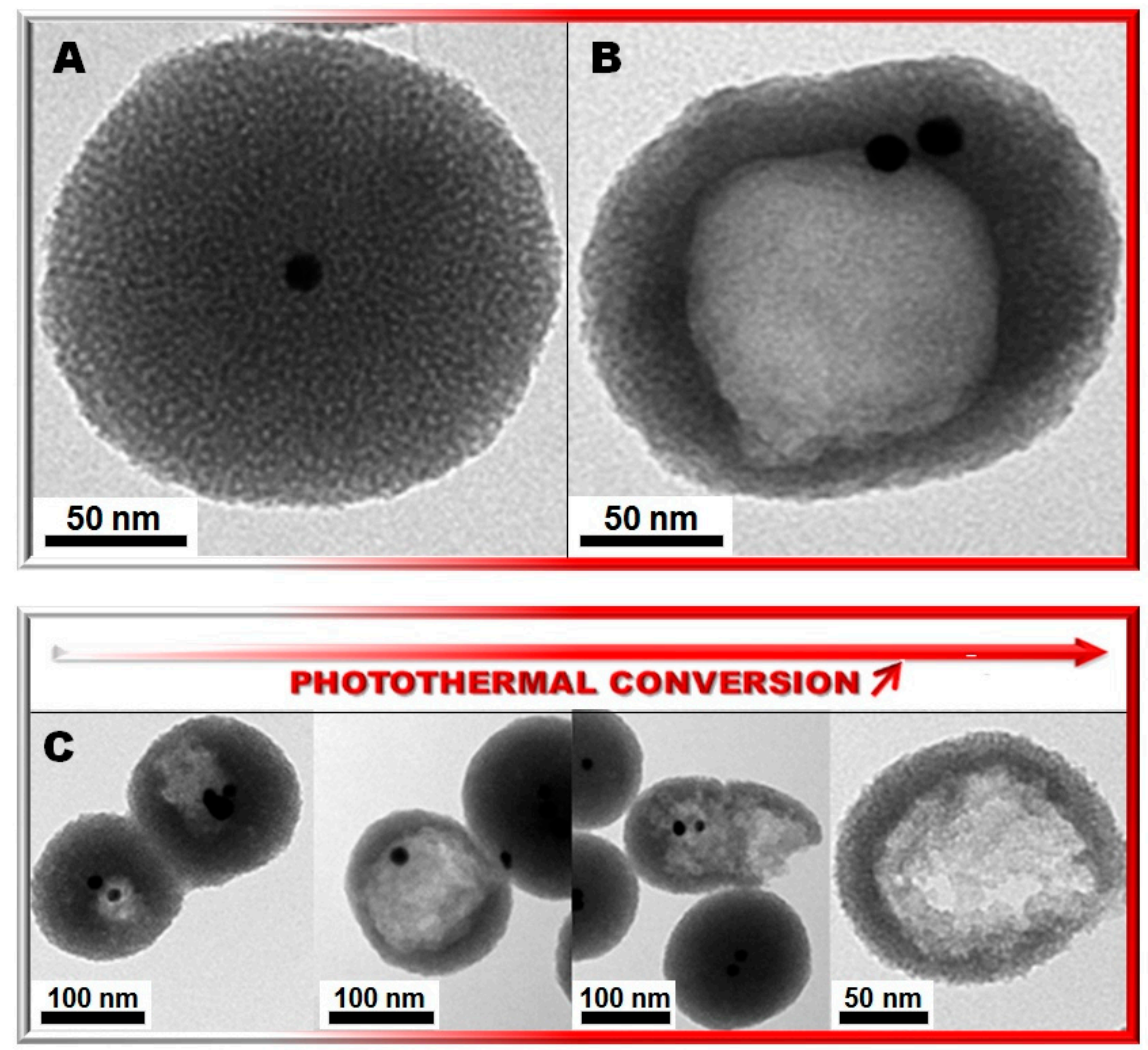

Figure 2. TEM images of Au@MSN before irradiation (A), and after $7 \mathrm{~h}$ of irradiation through an argon ion laser at $514 \mathrm{~nm}$ under $50 \mathrm{~mW}$ (B). Impact of the PT conversion of the gold cores on the MSN matrix under $50 \mathrm{~mW}(\mathbf{C})$. 
The influence of the laser power on the silica photodegradation was then evaluated. Au@MSN NPs were irradiated at $514 \mathrm{~nm}$ for $14 \mathrm{~h}$ under 15 and $100 \mathrm{~mW}$ (Figures 3A and 2B respectively). Lower power $(15 \mathrm{~mW})$ did not show any photodegradation, whereas TEM images displayed a complete silica photodegradation at higher power $(100 \mathrm{~mW})$. Note that bare MSN without gold cores were also irradiated at $514 \mathrm{~nm}$ under $100 \mathrm{~mW}$ for $14 \mathrm{~h}$ in a control experiment, and none of the NPs were damaged (Figure 3C). Importantly, we have already demonstrated plasmonic heating of at least $60^{\circ} \mathrm{C}$ inside Au@MSN in identical conditions (15 mW, $514 \mathrm{~nm}$ ) for cargo release applications [57], which implies that the integrity of the silica framework remains untouched under plasmonic PT effects until the local temperature is sufficiently high [57]. It should also be noted that the bulk temperature of the NPs solution did not significantly change before and after irradiation. Besides, as discussed in following sections, using powers of 20 to $30 \mathrm{~mW}$ (for $30 \mathrm{~min}$ or $7 \mathrm{~h}$ ) also lead to silica photocracking (Figures 4, 5 and $6 \mathrm{~F}$ ), while the photodegradation was much more severe for the same duration under $50 \mathrm{~mW}$ (Figure 2B,C). These observations confirm the power dependence of plasmonically-actuated silica degradation. Notably, gold NPs did not appear to degrade, unlike other studies using higher powers [56].

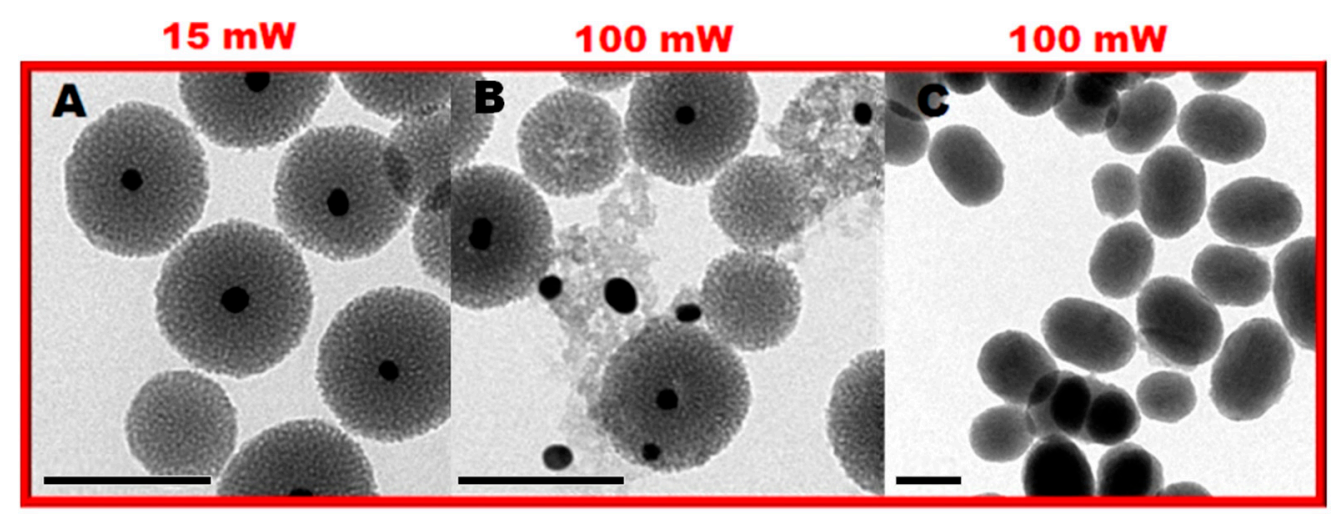

Figure 3. TEM images of Au@MSN irradiated $14 \mathrm{~h}$ at $514 \mathrm{~nm}$ under $15 \mathrm{~mW}$ (A), and $100 \mathrm{~mW}$ (B) displaying the power dependency of PT effect. Intact bare mesoporous silica NPs after irradiation for $14 \mathrm{~h}$ at $514 \mathrm{~nm}$ under $100 \mathrm{~mW}(\mathbf{C})$. Scale bars of $100 \mathrm{~nm}$ are used (A-C).

To study the influence of the laser wavelength and the diameter of gold cores on the silica photocracking, Au@MSN were prepared with polydisperse gold nanocores. This strategy allowed the rigorous assessment of the role of the size on the photocracking since all gold particles will have the same surface capping agents and will be encapsulated in an identical silica matrix, unlike multiple samples of Au@MSN obtained by different procedures to contain gold NPs of different sizes. Au@MSN with polydisperse gold nanocores (ca. 5-40 nm-wide) were characterized by TEM and DLS and displayed sizes of ca. $150 \mathrm{~nm}$, a surface area of ca. $960 \mathrm{~m}^{2} \cdot \mathrm{g}^{-1}$ and average pore sizes of $2.4 \mathrm{~nm}$ (Figures S4 and S5). The mesoporous silica shell had an average thickness of $133 \pm 14 \mathrm{~nm}$ (Figure S6). The polydispersity of gold nanocores was confirmed by the wider plasmon band in the UV-vis spectrum when compared to Au@MSN containing monodisperse $15 \mathrm{~nm}$-wide gold cores (Figure S7). The plasmonic heating was expected to correlate with the extinction coefficients of the gold NPs, which in turn is correlated with the gold particle diameter. Indeed, both the extinction coefficient and the wavelength of maximum extinction increase as the particle size increases, but the extinction coefficient is much more sensitive to the size than to the wavelength. For example, the plasmon band maxima $\left(\lambda_{\max }\right)$ and molar extinction coefficients $(\varepsilon)$ have been reported to be $\lambda_{\max }=524 \mathrm{~nm}$ and $\varepsilon=7 \times 10^{7} \mathrm{~L} \cdot \mathrm{mol}^{-1} \cdot \mathrm{cm}^{-1}, \lambda_{\max }=524 \mathrm{~nm}$ and $\varepsilon=78 \times 10^{7} \mathrm{~L} \cdot \mathrm{mol}^{-1} \cdot \mathrm{cm}^{-1}$, and $\lambda_{\max }=530 \mathrm{~nm}$ and $\varepsilon=$ $540 \times 10^{7} \mathrm{~L} \cdot \mathrm{mol}^{-1} \cdot \mathrm{cm}^{-1}$ for $7.5,16$, and $35 \mathrm{~nm}$-wide gold NPs, respectively [58].

To experimentally test this correlation, Au@MSN were initially irradiated at three different wavelengths $(448,530$, and $568 \mathrm{~nm}$ ) under $20 \mathrm{~mW}$ for $30 \mathrm{~min}$ to study the wavelength-dependence of the photodegradation (Figure $4 \mathrm{~A}$ ). In this experiment, a clear dependence on the irradiation wavelength 
on the mesoporous silica photodegradation was observed, since the silica shell was cracked at $530 \mathrm{~nm}$, while a hollow mesoporous silica nanostructure was generated at $568 \mathrm{~nm}$ (Figure S8). However, silica shells were surprisingly intact at $448 \mathrm{~nm}$ under the same power (Figure S8). This photodegradation was obtained after a relatively short time of irradiation (30 min), which demonstrated the efficiency of the process previously observed after $14 \mathrm{~h}$ of irradiation at $514 \mathrm{~nm}$ (Figure 2C). Secondly, irradiations at five different wavelengths were performed on Au@MSN (20 mW; $30 \mathrm{~min})$ and three size ranges (5-10, 15-20, and 25-35 nm) were compared (Figure 4). On the one hand, the 5-10 nm size range showed a slight degradation of the silica matrix at $448 \mathrm{~nm}$ (Figure 4A). On the other hand, the 25-35 nm size range did not exhibit silica degradation at these lower wavelengths, but the photocracking and dissolution of silica were observed at higher wavelengths (530 and $568 \mathrm{~nm}$, Figure 4C). The middle 15-20 nm size range displayed the silica photodegradation from 514-568 nm (Figure 4B). Such behavior is consistent with the plasmonic properties of gold nanocrystals of different sizes.

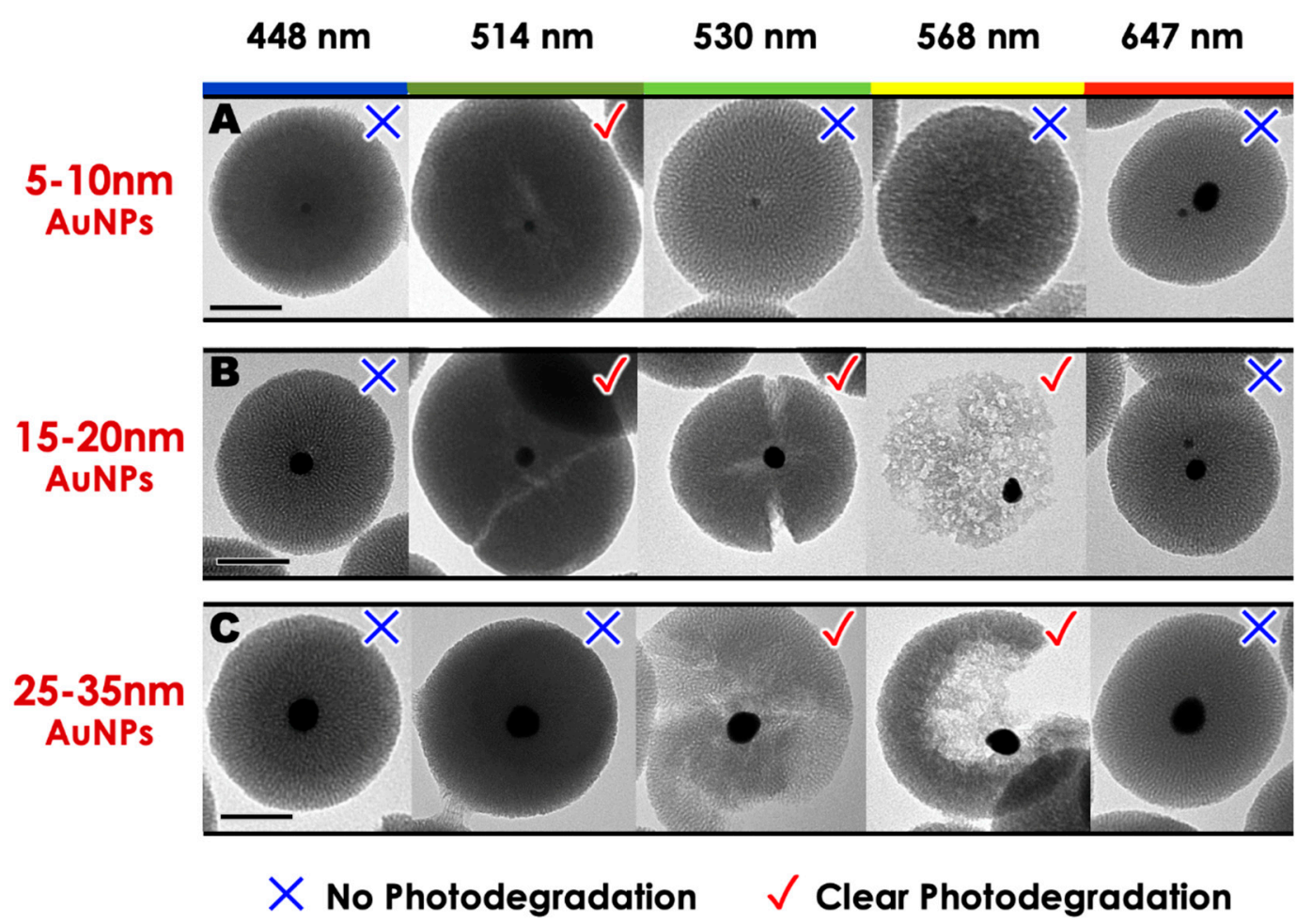

Figure 4. TEM images of three ranges of gold nanoparticle (NP) sizes in the mesoporous silica shells: 5-10 (A), 15-20 (B), and 25-35 nm (C) irradiated at five different wavelengths (448, 514, 530, 568, 647 $\mathrm{nm}$ ) under $20 \mathrm{~mW}$ for $30 \mathrm{~min}$. Representative most damaged NPs are presented for each size and wavelength. Scale bars of $50 \mathrm{~nm}$ are shown.

Several unique NPs in our experiments also suggested that gold NPs could be selectively excited by tuning the wavelength of irradiation. Figure 5 shows the unique case of two Au@MSN fused during the sol-gel process which contains two different 15 and 5 nm-wide gold cores sufficiently separated to be considered independent. Astonishingly, the photocracking of silica selectively occurred around the $15 \mathrm{~nm}$-wide care upon irradiation at $514 \mathrm{~nm}$, as predicted by the wavelength and size dependence observed in Figure 4. Note that the reverse situation was found in Figure S8A where 5 and $15 \mathrm{~nm}$-wide gold cores were encapsulated within one silica shell and the $448 \mathrm{~nm}$ irradiation revealed a slight local degradation around the $5 \mathrm{~nm}$ core, leaving the $15 \mathrm{~nm}$ core area intact. These observations strongly suggested that plasmonic particles can be selectively excited to photodegrade materials which open new horizons in selective photolithography or dual cargo release using fused twin core-shell nanosystems containing plasmonic particles of different sizes. 


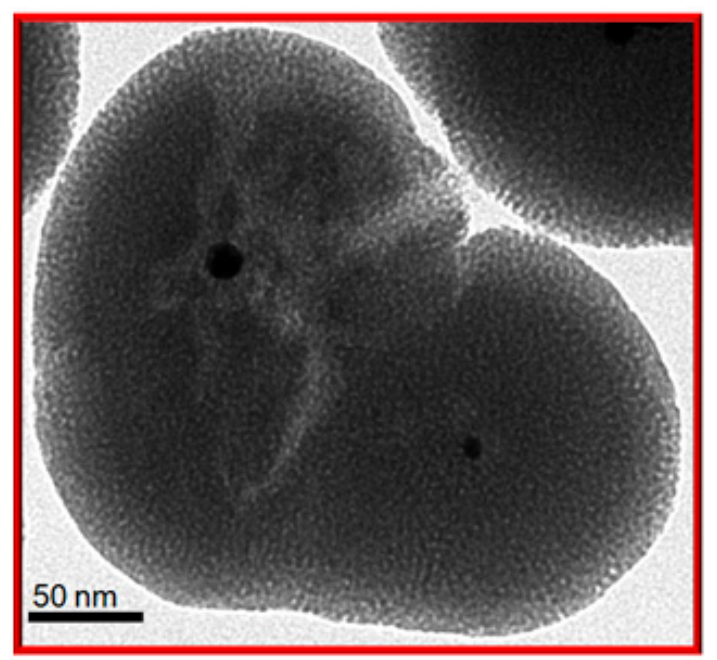

Figure 5. Selective plasmonic photodegradation based on the gold core diameter displayed by a unique TEM image of Au@MSN (7 h of irradiation; 514 nm; 30 mW).

The controlled plasmonic photodegradation of silica particles was finally applied for remote cargo release. Au@MSN nanomaterials with $15 \mathrm{~nm}$ cores were loaded with the rhodamine B dye in aqueous solution and then coated with an alkoxysilylated polycaprolactone (PCL, $2000 \mathrm{~g} \cdot \mathrm{mol}^{-1}$ ) to prevent the dye leakage (Figure 5A and Figure S9A). The alkoxysilylated PCL was obtained from the coupling of the commercial PCL diol with 3-(trimethoxysilyl)propyl isocyanate in toluene (ESI). The successful polymer coating onto Au@MSN was confirmed by TEM before (Figure 6B) and after PCL attachment (Figure 6C,D and Figure S10). This was further validated by Fourier transform infrared (FTIR) spectroscopy displaying the polymeric $v_{\mathrm{C}-\mathrm{H}}$ vibrational modes between 2950 and $2850 \mathrm{~cm}^{-1}$ and the $v_{\mathrm{C}=\mathrm{O}}$ carbonyl mode at $1692 \mathrm{~cm}^{-1}$ (Figure S9B). A rhodamine B payload of $3 \mathrm{wt} \%$ was calculated using UV-visible analysis of the loading supernatant. Then, dye-loaded Au@MSN@polymer were placed at the bottom of a quartz cuvette filled with deionized water and irradiated at $514 \mathrm{~nm}$ under $30 \mathrm{~mW}$ (Figure 6E). The flat baseline before laser irradiation was characteristic of a robust nanocarrier devoid of premature cargo leakage. When the laser was turned on, however, an instantaneous release of rhodamine B cargos was triggered (Figure 6E). The full release of cargos was reached after nearly $1000 \mathrm{~min}$.

Various analyses and control experiments were eventually performed to understand the mechanism of the cargo release. TEM analyses of the irradiated Au@MSN@polymer nanocarriers revealed that the release of the cargo was due to the photocracking of silica nanoshells (Figure 6F). The selection of PCL coating was also purposeful for its low melting temperature $\left(60^{\circ} \mathrm{C}\right)$ which corresponds to the local heating generated in our nanosystem $(30 \mathrm{~mW}$ at $514 \mathrm{~nm})$ [57]. A local temperature increase of at least $60^{\circ} \mathrm{C}$ within Au@MSN@polymer NPs working in tandem with the photocracking of silica thus accounts for the release of cargos under irradiation. Two control experiments were carried out to confirm (i) the thermo-responsiveness of the coating of Au@MSN@polymer particles and (ii) the loading of cargos into silica pores rather than into the polymer shell. First, cargo-loaded Au@MSN@polymer particles were placed into an oil bath at $60^{\circ} \mathrm{C}$ to evaluate the thermo-responsiveness of PCL. Consistent with our expectations, no cargos were released before heating the particles and when the external heating was turned on, the release of cargos occurred (Figure S12). Secondly, solid (non-mesoporous) Stöber silica NPs were synthesized [61] (see TEM images in Figure S11) along with bare mesoporous silica particles [57]. Both particle types were mixed with Rhodamine B cargos overnight and then coated with silylated PCL molecules. Release experiments were then conducted with the oil bath set again at $60{ }^{\circ} \mathrm{C}$ (Figure S13). Stöber silica@polymer particles released only $0.01 \mathrm{wt} \%$ of cargos whereas MSN@polymer released ca. $2.02 \mathrm{wt} \%$ which demonstrated that most cargo molecules were loaded into the pores of silica particles rather than into the polymeric shell. We concluded that these experiments 
and characterizations confirmed a release mechanism involving the PT melting of PCL synergistically with the silica photocracking.

A

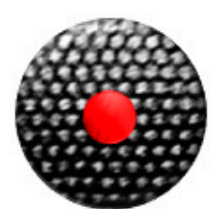

Au@MSN

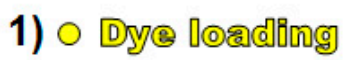

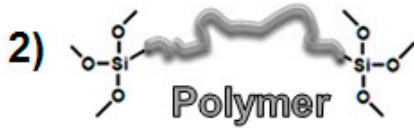

\section{Au@MSN@Polymor}

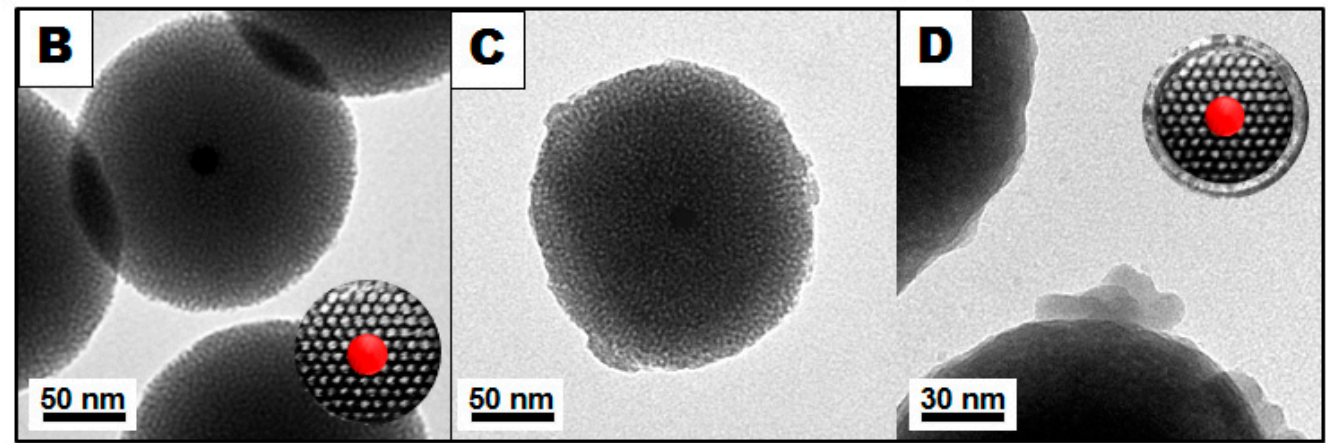

$\mathbf{E}$
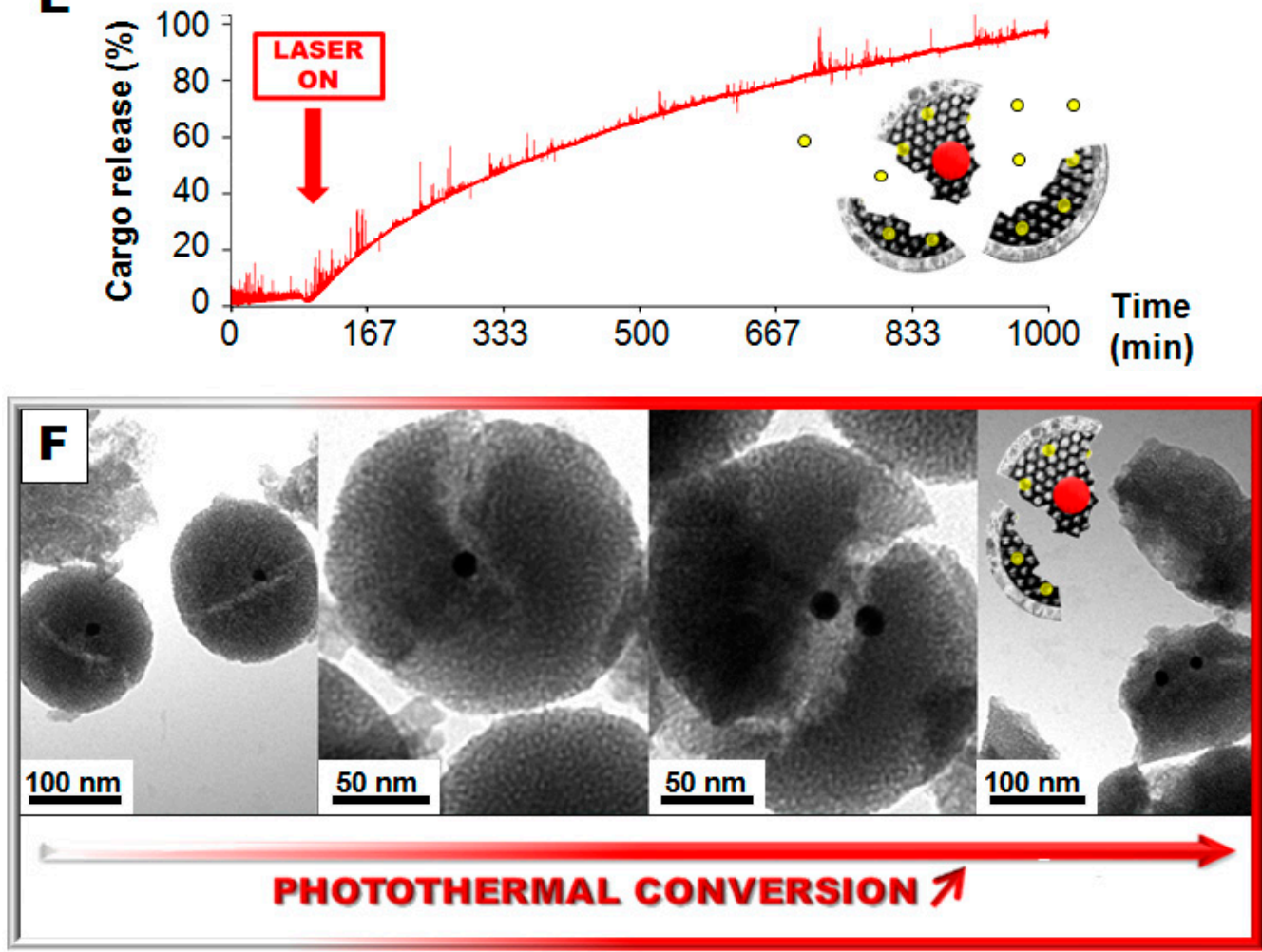

Figure 6. Schematic representation of the dye loading and polymer coating of Au@MSN (A). TEM micrographs before (B) and after polymer coating (C,D). Light-triggered cargo release in solution (514 nm, 30 mW) (E). TEM photodegradation of the dye-loaded Au@MSN@polymer nanoparticles after $7 \mathrm{~h}$ of release experiment $(\mathbf{F})$.

\section{Materials and Methods}

Materials. Potassium tetrachloroaurate $(99 \%+)$ was purchased from Alfa Aesar (Ward Hill, MA, USA). Sodium citrate tribasic dihydrate $(99 \%+)$, cetyltrimethylammonium bromide $(\mathrm{CTAB}, 99 \%+)$, 
tetraethylorthosilicate (TEOS), and 3-aminopropyltrimethoxysilane (APTMS) were purchased from Sigma-Aldrich (St. Louis, MO, USA). Sodium hydroxide (beads) was purchased from Fisher Scientific (Pittsburgh, PA, USA).

Laser Irradiation. A COHERENT CUBE 445-40C diode laser (Santa Clara, CA, USA) was used to irradiate Au@MSN NPs at $448 \mathrm{~nm}$. A COHERENT Argon Innova 90C-5 ion laser (Santa Clara, CA, USA) was applied to excite Au@MSN NPs at $514 \mathrm{~nm}$. A COHERENT Ar $/ \mathrm{Kr}^{+}$laser (Santa Clara, CA, USA) was applied on Au@MSN NPs at 530, 568, and $647 \mathrm{~nm}$. The powers of irradiations specified in the article $(15,20,30,50$, and $100 \mathrm{~mW})$ take into account the different mirrors, lenses, and glass objects in the path the laser beam. The laser spot was half of a centimeter in diameter; thus, the Au@MSN were submitted to 0.06, 0.08, 0.12, 0.2, and 0.4 W/cm². A dried powder of Au@MSN or Au@MSN@Polymer ( 2 mg) was deposited at the bottom of a quartz cuvette. A controlled amount of deionized water $(2 \mathrm{~mL})$ was then slowly added using a micropipette to avoid dispersing the particles. The selected laser was then directed at the powder and the degradation or release experiments were carried out. In this configuration, not all NPs receive the same number of photons, but it enabled the simultaneous tracking of cargo molecules released from the NPs without disturbing the system (change of concentration or dispersion, etc).

Au NPs 15 nm. Monodisperse Au NPs were obtained from the reported Turkevich method involving the reduction of potassium tetrachloroaurate complexes $(55 \mathrm{mg}, 11 \mathrm{mM})$ via the injection of sodium tribasic citrate reducing agent $(120 \mathrm{mg}, 40 \mathrm{mM})$ in boiling water $(100 \mathrm{~mL})$ for $5 \mathrm{~min}$ [59]. The resulting solution A was utilized without further preparation.

Au@MSN with Monodisperse Cores. An aqueous solution $(90 \mathrm{~mL})$ of sodium hydroxide $(875 \mu \mathrm{L}$, $2 \mathrm{M})$, and CTAB $(250 \mathrm{mg})$ was stirred vigorously at $80^{\circ} \mathrm{C}$. Then, a solution of $15 \mathrm{~nm}$ Au NPs $(30 \mathrm{~mL}$ of A) was added to the aforementioned mixture. Finally, TEOS $(1200 \mu \mathrm{L})$ was added by consecutive dropwise additions. The sol-gel process was conducted for $2 \mathrm{~h}$. Afterward, the solution was cooled at room temperature while stirring; fractions were gathered in propylene tubes and collected by centrifugation during $15 \mathrm{~min}$ at $21 \mathrm{krpm}$. The sample was then extracted twice with an alcoholic solution of ammonium nitrate $\left(6 \mathrm{~g} \cdot \mathrm{L}^{-1}, \mathrm{NH}_{4} \mathrm{NO}_{3}\right)$, and washed three times with ethanol, water, and ethanol. Each extraction involved a sonication step of $30 \mathrm{~min}$ at $50^{\circ} \mathrm{C}$ in order to remove the CTAB surfactant; the collection was carried out in the same manner. The as-prepared material was dried under air flow for a few hours.

Au@MSN with Polydisperse Cores. Such a procedure was adapted from a reported one-pot process of Au@MSN NPs [57]. A mixture of water $(100 \mathrm{~mL})$, ethanol $(40 \mathrm{~mL})$, and CTAB $(0.640 \mathrm{~g})$, and potassium tetrachloroaurate $(55 \mathrm{mg})$ was stirred at $70{ }^{\circ} \mathrm{C}$ in a three neck $250 \mathrm{~mL}$ round bottom flask. Secondly, sodium hydroxide $(200 \mu \mathrm{L}, 2 \mathrm{M})$ was injected to produce the nucleation of the NPs nucleation instantaneously. The NPs growth was conducted for 30 min under $600 \mathrm{rpm}$. Afterward, TEOS $(1000 \mu \mathrm{L})$ was added by dropwise additions to the stirred aforementioned solution. Then, the condensation process was triggered by a second addition of sodium hydroxide $(400 \mu \mathrm{L}, 2 \mathrm{M})$. After $1 \mathrm{~min} 30 \mathrm{~s}$, the typical purple color of thin coated Au@MSN particles was observed, and the sol-gel process was conducted for $2 \mathrm{~h}$. The material was collected through centrifugation at $7830 \mathrm{rpm}$ for $15 \mathrm{~min}$. Each fraction was washed with $\mathrm{MeOH}(40 \mathrm{~mL})$ and centrifuged $10 \mathrm{~min}$, three times. The sample was then extracted twice with an alcoholic solution of $\mathrm{NH}_{4} \mathrm{NO}_{3}\left(6 \mathrm{~g} \cdot \mathrm{L}^{-1}\right)$, and washed three times with ethanol, water, and ethanol. Each extraction involved a sonication step of $30 \mathrm{~min}$ at $50^{\circ} \mathrm{C}$ in order to remove $\mathrm{CTAB}$; the collection was carried out in the same manner. The as-prepared material was dried under air flow for a few hours.

Au@MSN@PCL Polymer. To prepare the silylated PCL polymer used for the mesoporous silica coating, a mixture of PCL diol (ca. $2000 \mathrm{~g} \cdot \mathrm{mol}^{-1}$ ) was mixed with two equivalents of 3-(triethoxysilyl)propyl isocyanate $95 \%$ in toluene $(50: 1, v: v)$. The solution was refluxed overnight (the reaction spontaneously occurs at high temperature). The solution was then cooled and kept in a fridge to be used without further purification. For the polymer coating reaction, a controlled volume of silylated PCL in toluene was added to Au@MSN ( 3:100, w:w), and the coupling was obtained at room temperature by stirring 
overnight without a catalyst. The Au@MSN@PCL particles were finally washed twice with water, dried under air, and used for degradation or release experiments. In the case of cargo-loaded Au@MSN@PCL NPs, cargo molecules ( 2-3 mg) were first mixed with Au@MSN ( 10 mg) and stirred overnight. The next day, silylated PCL was added to the mixture and the same procedure described above was applied.

\section{Conclusions}

In summary, we reported for the first time the photocracking of silica particles using plasmonic photothermal effects in an Au@MSN nanosystem. The photocracking and advanced dissolution of silica particles were observed by electron microscopy after $30 \mathrm{~min}$ of irradiation under low power continuous wave irradiation (e.g., $30 \mathrm{~mW}$ ), and the same results were also observed after only one minute of laser excitation (data not shown). The silica shell photodegradation was controlled through tuning the power and wavelength of the laser, or by tuning the size of gold nanocores at a given wavelength. In the future, quantitative photodegradation studies could be performed by changing the irradiation setup using stirred particle dispersions with low-volume cuvettes.

Regarding the photodegradation mechanism, since calcination methods abound to remove molecular templates from mesoporous silica and none of them have ever caused the cracking of silica, it follows that temperature alone does not account for the cracking silica, at least up to $600{ }^{\circ} \mathrm{C}$. We believe that the photocracking of silica perhaps occurs in a process similar to thermal fracturing in glass. When a temperature differential is rapidly created within glass, the silicon dioxide network fractures. Another component that may play a concomitant role in the photodegradation is the potential vibration of plasmonic cores. Nonetheless, the silica photocracking mechanism remains largely unknown.

The unique plasmonic photocracking of silica was then successfully harnessed to controllably release cargo molecules encapsulated within Au@MSN@Polycaprolactone nanovectors. The tripartite nanovectors were cracked much like "nano-eggs" to release cargos upon laser actuation. Future works could apply the photothermal cracking of silica for the delivery of drugs with enhanced cytotoxicity under hyperthermia such as Docetaxel ${ }^{\mathrm{TM}}$ [62]. Multiple drug delivery could be obtained using non-symmetrical nanoplatforms having gold nanocores of various sizes thanks to the wavelength dependence. Besides, using NIR-sensitive nanocores, such as gold nanorods or nanoshells, would enable drug delivery upon photocracking in the NIR I or NIR II region for clinical applications. One could also envision the use of plasmonic photocracking for selective photopatterning. All in all, these findings open new horizons for the design of biocompatible inorganic drug delivery nanosystems with remote-controlled plasmonic photodegradation to prevent particle bioaccumulation and promote innovative therapeutic solutions.

Supplementary Materials: The following are available online at http://www.mdpi.com/2304-6740/7/6/72/s1, Figure S1: Transmission electron microscopy (TEM) images of monodisperse $15 \mathrm{~nm}$ gold nanospheres obtained by the citrate method (A) and the monodisperse Au@MSN after the core-shell synthesis (B,C), Figure S2: Nitrogen sorption isotherm of Au@MSN obtained with $15 \mathrm{~nm}$ monodisperse gold nanospheres (citrate method). Figure S3. Histogram plotting the distribution of mesoporous silica shell thickness for Au@MSN containing monosized $15 \mathrm{~nm}$-wide Au NP cores. Plotted by analyzing nanomaterials in multiple TEM images, Figure S4: TEM images of monodisperse $15 \mathrm{~nm}$ gold nanospheres obtained by the citrate method (A) and the monodisperse Au@MSN after the core-shell synthesis (B,C), Figure S5: Nitrogen sorption isotherm of Au@MSN obtained with polydisperse gold nanospheres (in-situ method), Figure S6: Histogram plotting the distribution of mesoporous silica shell thickness for Au@MSN containing polydisperse Au NP cores. Plotted by analyzing nanomaterials in multiple TEM images, Figure S7: Extinction spectra of Au@MSN obtained with $15 \mathrm{~nm}$ monodisperse gold nanospheres (citrate method, A) and polydisperse gold nanospheres (in-situ method, B). Accordingly, the plasmon band of the citrate method is narrower, Figure S8: Wavelength dependence of the plasmonic photothermal cracking of silica demonstrated by the TEM images of irradiated Au@MSN at different wavelengths: 448 (A), 530 (B), and $568 \mathrm{~nm}$ (C) under $20 \mathrm{~mW}$ for 30 minutes, Figure S9: Representation of the Au@MSN@Polymer structure (A) and FTIR spectra confirming the polymer coating of Au@MSN, Figure S10: Representative TEM image of Au@MSN@Polymer confirming that surface coating of polycaprolactone on the particles, Figure S11: TEM images of solid silica nanoparticle control (non-porous equivalent used to demonstrate the loading of the cargos mainly inside the pores of MSN), Figure S12: Thermo-induced controlled release profile of Au@MSN@ loaded with Coumarin 440. This control experiment confirms that the release of cargos is thermo-sensitive, consistent with the properties of polycaprolactone (melting 
point: $60^{\circ} \mathrm{C}$ ), Figure S13: Thermo-induced controlled release profile of non-porous and porous silica nanoparticles coated with the polymer and loaded with rhodamine $B$ dyes $\left(\Delta \mathrm{Abs}_{\max }\right.$ at $\left.\lambda=553 \mathrm{~nm}\right)$. This control experiment shows that the loading of cargos inside polymer-coated MSN mainly occurs inside the silica pores and not inside the polycaprolactone polymer shells.

Author Contributions: The concept, experiments, and manuscript preparation were realized by J.G.C. The release experiment was conducted by T.M.G.-A.

Funding: We gratefully acknowledge the research funding by the University of California, Los Angeles (UCLA) and the University of New Mexico (UNM).

Acknowledgments: The authors thank Jeffrey I. Zink for helpful discussions. This work made use of the research facilities of the University of California, Los Angeles (UCLA) and the California NanoSystems Institute at UCLA.

Conflicts of Interest: The authors declare no conflict of interest.

\section{References}

1. Croissant, J.G.; Fatieiev, F.; Khashab, N.M. Degradability and clearance of silicon, organosilica, silsesquioxane, silica mixed oxide, and mesoporous silica nanoparticles. Adv. Mater. 2017, 29, 1604634. [CrossRef] [PubMed]

2. Croissant, J.G.; Brinker, C.J. Biodegradable silica-based nanoparticles: Dissolution kinetics and selective bond cleavage. In The Enzymes; Elsevier: Amsterdam, The Netherlands, 2018; Volume 43, pp. 181-214.

3. Croissant, J.; Cattoën, X.; Wong Chi Man, M.; Gallud, A.; Raehm, L.; Trens, P.; Maynadier, M.; Durand, J.O. Biodegradable ethylene-bis(propyl)disulfide-based periodic mesoporous organosilica nanorods and nanospheres for efficient in-vitro drug delivery. Adv. Mater. 2014, 26, 6174-6180. [CrossRef] [PubMed]

4. Yang, G.; Phua, S.Z.F.; Bindra, A.K.; Zhao, Y. Degradability and clearance of inorganic nanoparticles for biomedical applications. Adv. Mater. 2019, 31, 1805730. [CrossRef] [PubMed]

5. Ruiz-Hitzky, E.; Ariga, K.; Lvov, Y.M. Bio-Inorganic Hybrid Nanomaterials: Strategies, Synthesis, Characterization and Applications; John Wiley \& Sons: Hoboken, NJ, USA, 2018.

6. Croissant, J.G.; Fatieiev, Y.; Almalik, A.; Khashab, N.M. Mesoporous silica and organosilica nanoparticles: Physical chemistry, biosafety, delivery strategies, and biomedical applications. Adv. Health. Mater. 2018, 7, 1700831. [CrossRef] [PubMed]

7. Croissant, J.G.; Cattoën, X.; Wong Chi Man, M.; Durand, J.O.; Khashab, N.M. Syntheses and applications of periodic mesoporous organosilica nanoparticles. Nanoscale 2015, 7, 20318-20334. [CrossRef] [PubMed]

8. Croissant, J.; Cattoën, X.; Wong Chi Man, M.; Dieudonné, P.; Charnay, C.; Raehm, L.; Durand, J.O. One-pot construction of multipodal hybrid periodic mesoporous organosilica nanoparticles with crystal-like architectures. Adv. Mater. 2015, 27, 145-149. [CrossRef] [PubMed]

9. Egger, S.M.; Hurley, K.R.; Datt, A.; Swindlehurst, G.; Haynes, C.L. Ultraporous mesostructured silica nanoparticles. Chem. Mater. 2015, 27, 3193-3196. [CrossRef]

10. Zhang, K.; Xu, L.L.; Jiang, J.G.; Calin, N.; Lam, K.F.; Zhang, S.J.; Wu, H.H.; Wu, G.D.; Albela, B.; Bonneviot, L.; et al. Facile large-scale synthesis of monodisperse mesoporous silica nanospheres with tunable pore structure. J. Am. Chem. Soc. 2013, 135, 2427-2430. [CrossRef]

11. Yu, L.; Chen, Y.; Wu, M.; Cai, X.; Yao, H.; Zhang, L.; Chen, H.; Shi, J. “Manganese extraction” strategy enables tumor-sensitive biodegradability and theranostics of nanoparticles. J. Am. Chem. Soc. 2016, 138, 9881-9894. [CrossRef]

12. Hao, X.; Hu, X.; Zhang, C.; Chen, S.; Li, Z.; Yang, X.; Liu, H.; Jia, G.; Liu, D.; Ge, K.; et al. Hybrid mesoporous silica-based drug carrier nanostructures with improved degradability by hydroxyapatite. ACS Nano 2015, 9 , 9614-9625. [CrossRef]

13. Croissant, J.G.; Fatieiev, Y.; Julfakyan, K.; Lu, J.; Emwas, A.H.; Anjum, D.H.; Omar, H.; Tamanoi, F.; Zink, J.I.; Khashab, N.M. Biodegradable oxamide-phenylene-based mesoporous organosilica nanoparticles with unprecedented drug payloads for delivery in cells. Chem. Eur. J. 2016, 22, 14806-14811. [CrossRef] [PubMed]

14. Maggini, L.; Travaglini, L.; Cabrera, I.; Castro-Hartmann, P.; De Cola, L. Biodegradable peptide-silica nanodonuts. Chem. Eur. J. 2016, 22, 3697-3703. [CrossRef]

15. Croissant, J.G.; Mauriello-Jimenez, C.; Maynadier, M.; Cattoën, X.; Wong Chi Man, M.; Raehm, L.; Mongin, O.; Blanchard-Desce, M.; Garcia, M.; Gary-Bobo, M.; et al. Synthesis of disulfide-based biodegradable bridged silsesquioxane nanoparticles for two-photon imaging and therapy of cancer cells. Chem. Commum. 2015, 51, 12324-12327. [CrossRef] [PubMed] 
16. Zhou, M.; Du, X.; Li, W.; Li, X.; Huang, H.; Liao, Q.; Shi, B.; Zhang, X.; Zhang, M. One-pot synthesis of redox-triggered biodegradable hybrid nanocapsules with a disulfide-bridged silsesquioxane framework for promising drug delivery. J. Mater. Chem. B 2017, 5, 4455-4469. [CrossRef]

17. Moghaddam, S.P.H.; Yazdimamaghani, M.; Ghandehari, H. Glutathione-sensitive hollow mesoporous silica nanoparticles for controlled drug delivery. J. Control. Release 2018, 282, 62-75. [CrossRef]

18. Du, X.; Kleitz, F.; Li, X.; Huang, H.; Zhang, X.; Qiao, S.Z. Disulfide-bridged organosilica frameworks: Designed, synthesis, redox-triggered biodegradation, and nanobiomedical applications. Adv. Funct. Mater. 2018, 28, 1707325. [CrossRef]

19. Omar, H.; Croissant, J.G.; Alamoudi, K.; Alsaiari, S.; Alradwan, I.; Majrashi, M.A.; Anjum, D.H.; Martins, P.; Laamarti, R.; Eppinger, J.; et al. Biodegradable magnetic silica@iron oxide nanovectors with ultra-large mesopores for high protein loading, magnetothermal release, and delivery. J. Control. Release 2017, 259, 187-194. [CrossRef]

20. Pohaku Mitchell, K.K.; Liberman, A.; Kummel, A.C.; Trogler, W.C. Iron(III)-doped, silica nanoshells: A biodegradable form of silica. J. Am. Chem. Soc. 2012, 134, 13997-14003. [CrossRef]

21. Peng, Y.K.; Tseng, Y.J.; Liu, C.L.; Chou, S.W.; Chen, Y.W.; Tsang, S.E.; Chou, P.T. One-step synthesis of degradable $T_{1}$-FeOOH functionalized hollow mesoporous silica nanocomposites from mesoporous silica spheres. Nanoscale 2015, 7, 2676-2687. [CrossRef]

22. Wang, L.; Huo, M.; Chen, Y.; Shi, J. Iron-engineered mesoporous silica nanocatalyst with biodegradable and catalytic framework for tumor-specific therapy. Biomaterials 2018, 163, 1-13. [CrossRef]

23. Fu, Y.; Jiang, Y.B.; Dunphy, D.; Xiong, H.; Coker, E.; Chou, S.; Zhang, H.; Vanegas, J.M.; Croissant, J.G.; Cecchi, J.L.; et al. Ultra-thin enzymatic liquid membrane for $\mathrm{CO}_{2}$ separation and capture. Nat. Commum. 2018, 9, 990. [CrossRef] [PubMed]

24. De Vos, R.M.; Maier, W.F.; Verweij, H. Hydrophobic silica membranes for gas separation. J. Membr. Sci. 1999, 158, 277-288. [CrossRef]

25. Hoffmann, F.; Cornelius, M.; Morell, J.; Fröba, M. Silica-based mesoporous organic-inorganic hybrid materials. Angew. Chem. Int. Ed. 2006, 45, 3216-3251. [CrossRef]

26. Ma, Y.; Qi, L.; Ma, J.; Wu, Y.; Liu, O.; Cheng, H. Large-pore mesoporous silica spheres: Synthesis and application in HPLC. Colloids Surf. A 2003, 229, 1-8. [CrossRef]

27. Heaney, P.J.; Prewitt, C.T.; Gibbs, G.V. (Eds.) Silica: Physical Behavior, Geochemistry, and Materials Applications; Walter de Gruyter GmbH \& Co KG: Berlin, Germany, 2018; Volume 29.

28. Margelefsky, E.L.; Zeidan, R.K.; Davis, M.E. Cooperative catalysis by silica-supported organic functional groups. Chem. Soc. Rev. 2008, 37, 1118-1126. [CrossRef]

29. Croissant, J.G.; Zink, J.I.; Raehm, L.; Durand, J.O. Two-photon-excited silica and organosilica nanoparticles for spatiotemporal cancer treatment. Adv. Health. Mater. 2018, 7, 1701248. [CrossRef] [PubMed]

30. Mauriello Jimenez, C.; Aggad, D.; Croissant, J.G.; Tresfield, K.; Laurencin, D.; Berthomieu, D.; Cubedo, N.; Rossel, M.; Alsaiari, S.; Anjum, D.H.; et al. Porous porphyrin-based organosilica nanoparticles for NIR two-photon photodynamic therapy and gene delivery in zebrafish. Adv. Funct. Mater. 2017, 28, 1800235. [CrossRef]

31. Zhou, Y.; Quan, G.; Wu, Q.; Zhang, X.; Niu, B.; Wu, B.; Huang, Y.; Pan, X.; Wu, C. Mesoporous silica nanoparticles for drug and gene delivery. Acta Pharm. Sin. B 2018, 8, 165-177. [CrossRef]

32. Rühle, B.; Saint-Cricq, P.; Zink, J.I. Externally controlled nanomachines on mesoporous silica nanoparticles for biomedical applications. ChemPhysChem 2016, 17, 1769-1779. [CrossRef]

33. Dogra, P.; Adolphi, N.L.; Wang, Z.; Lin, Y.S.; Butler, K.S.; Durfee, P.N.; Croissant, J.G.; Noureddine, A.; Coker, E.N.; Bearer, E.L.; et al. Establishing the effects of mesoporous silica nanoparticle properties on in vivo disnmposition using imaging-based pharmacokinetics. Nat. Commum. 2018, 9, 4551. [CrossRef] [PubMed]

34. Chen, Y.; Chen, H.; Shi, J. In vivo bio-safety evaluations and diagnostic/therapeutic applications of chemically designed mesoporous silica nanoparticles. Adv. Mater. 2013, 25, 3144-3176. [CrossRef]

35. Lee, D.; Beack, S.; Yoo, J.; Kim, S.K.; Lee, C.; Kwon, W.; Hahn, S.K.; Kim, C. In Vivo Photoacoustic Imaging of Livers Using Biodegradable Hyaluronic Acid-Conjugated Silica Nanoparticles. Adv. Mater. 2018, 28, 1800941. [CrossRef]

36. Zhou, W.; Gao, X.; Liu, D.; Chen, X. Gold nanoparticles for in vitro diagnostics. Chem. Rev. 2015, 115, 10575-10636. [CrossRef] 
37. Amendola, V.; Pilot, R.; Frasconi, M.; Marago, O.M.; Iati, M.A. Surface plasmon resonance in gold nanoparticles: A review. J. Phys. Condens. Matter 2017, 29, 203002. [CrossRef]

38. Daraee, H.; Eatemadi, A.; Abbasi, E.; Fekri Aval, S.; Kouhi, M.; Akbarzadeh, A. Application of gold nanoparticles in biomedical and drug delivery. Artif. Cells Nanomed. Biotechnol. 2016, 44, 410-422. [CrossRef]

39. Jain, P.K.; Huang, X.; El-Sayed, I.H.; El-Sayed, M.A. Noble metals on the nanoscale: Optical and photothermal properties and some applications in imaging, sensing, biology, and medicine. Acc. Chem. Res. 2008, 41, 1578-1586. [CrossRef]

40. Dykman, L.; Khlebtsov, N. Gold nanoparticles in biomedical applications: Recent advances and perspectives. Chem. Soc. Rev. 2012, 41, 2256-2282. [CrossRef]

41. Stewart, M.E.; Anderton, C.R.; Thompson, L.B.; Maria, J.; Gray, S.K.; Rogers, J.A.; Nuzzo, R.G. Nanostructured plasmonic sensors. Chem. Rev. 2008, 108, 494-521. [CrossRef]

42. Lu, X.; Rycenga, M.; Skrabalak, S.E.; Wiley, B.; Xia, Y. Chemical synthesis of novel plasmonic nanoparticles. Annu. Rev. Phys. Chem. 2009, 60, 167-192. [CrossRef]

43. Homola, J.; Yee, S.S.; Gauglitz, G. Surface plasmon resonance sensors. Sens. Actuators B Chem. 1999, 54, 3-15. [CrossRef]

44. Liu, G.L.; Kim, J.; Lu, Y.; Lee, L.P. Optofluidic control using photothermal nanoparticles. Nat. Mater. 2006, 5, 27-32. [CrossRef]

45. Rycenga, M.; Wang, Z.; Gordon, E.; Cobley, C.M.; Schwartz, A.G.; Lo, C.S.; Xia, Y. Probing the photothermal effect of gold-based nanocages with surface-enhanced Raman scattering (SERS). Angew. Chem. Int. Ed. 2009, 48, 9924-9927. [CrossRef]

46. Raji, V.; Kumar, J.; Rejiya, C.S.; Vibin, M.; Shenoi, V.N.; Abraham, A. Selective photothermal efficiency of citrate capped gold nanoparticles for destruction of cancer cells. Exp. Cell Res. 2011, 317, 2052-2058. [CrossRef]

47. Jones, M.R.; Millstone, J.E.; Giljohann, D.A.; Seferos, D.S.; Young, K.L.; Mirkin, C.A. Plasmonically controlled nucleic acid dehybridization with gold nanoprisms. ChemPhysChem 2009, 10, 1461-1465. [CrossRef]

48. Zeng, N.; Murphy, A.B. Heat generation by optically and thermally interacting aggregates of gold nanoparticles under illumination. Nanotechnology 2009, 20, 375702. [CrossRef]

49. Haiss, W.; Thanh, N.T.K.; Aveyard, J.; Fernig, D.G. Determination of size and concentration of gold nanoparticles from UV-Vis spectra. Anal. Chem. 2007, 79, 4215-4221. [CrossRef]

50. Jain, P.K.; Lee, K.S.; El-Sayed, I.H.; El-Sayed, M.A. Calculated absorption and scattering properties of gold nanoparticles of different size, shape, and composition: Applications in biological imaging and biomedicine. J. Phys. Chem. B 2006, 110, 7238-7248. [CrossRef]

51. Hleb, E.Y.; Lapotko, D.O. Photothermal properties of gold nanoparticles under exposure to high optical energies. Nanotechnology 2008, 19, 355702. [CrossRef]

52. Zhang, G.; Yang, Z.; Lu, W.; Zhang, R.; Huang, Q.; Tian, M.; Li, L.; Liang, D.; Li, C. Influence of anchoring ligands and particle size on the colloidal stability and in vivo biodistribution of polyethylene glycol-coated gold nanoparticles in tumor-xenografted mice. Biomaterials 2009, 30, 1928-1936. [CrossRef]

53. Paasonen, L.; Laaksonen, T.; Johans, C.; Yliperttula, M.; Kontturi, K.S.; Urtti, A. Gold nanoparticles enable selective light-induced contents release from liposomes. J. Control. Release 2007, 122, 86-93. [CrossRef]

54. Angelatos, A.S.; Radt, B.; Caruso, F. Light-responsive polyelectrolyte/gold nanoparticle microcapsules. J. Phys. Chem. B 2005, 109, 3071-3076. [CrossRef] [PubMed]

55. Liu, S.; Han, M.Y. Silica-coated metal nanoparticles. Chem. Asian J. 2010, 5, 36-45. [CrossRef] [PubMed]

56. Prasad, V.; Mikhailovsky, A.; Zasadzinski, J.A. Inside-out disruption of silica/gold core-shell nanoparticles by pulsed laser irradiation. Langmuir 2005, 21, 7528-7532. [CrossRef]

57. Croissant, J.; Zink, J.I. Nanovalve-controlled cargo release activated by plasmonic heating. J. Am. Chem. Soc. 2012, 134, 7628-7631. [CrossRef] [PubMed]

58. Jana, N.R.; Gearheart, L.; Murphy, C.J. Seeding growth for size control of 5-40 nm diameter gold nanoparticles. Langmuir 2001, 17, 6782-6786. [CrossRef]

59. Turkevich, J.; Stevenson, P.C.; Hillier, J. A study of the nucleation and growth processes in the synthesis of colloidal gold. Discuss. Faraday Soc. 1951, 11, 55-75. [CrossRef]

60. Enustun, B.V.; Turkevich, J. Coagulation of colloidal gold. J. Am. Chem. Soc. 1963, 85, 3317-3328. [CrossRef] 
61. Nozawa, K.; Gailhanou, H.; Raison, L.; Panizza, P.; Ushiki, H.; Sellier, E.; Delville, J.P.; Delville, M.H. Smart control of monodisperse Stöber silica particles: Effect of reactant addition rate on growth process. Langmuir 2005, 21, 1516-1523. [CrossRef]

62. Mohamed, F.; Marchettini, P.; Stuart, O.A.; Urano, M.; Sugarbaker, P. Thermal enhancement of new chemotherapeutic agents at moderate hyperthermia. Ann. Surg. Oncol. 2003, 10, 463-468. [CrossRef] 